Published in final edited form as:

J Allergy Clin Immunol. 2017 December ; 140(6): 1683-1692. doi:10.1016/j.jaci.2017.09.032.

\title{
Advances in Environmental and Occupational Disorders 2016
}

\author{
William J. Sheehan, MD ${ }^{a, b}$, Jonathan M. Gaffin, MD, MMSc ${ }^{b, c}$, David B. Peden, MD, MSc ${ }^{d}$, \\ Robert K. Bush, MD ${ }^{\mathrm{e}}$, and Wanda Phipatanakul, MD, MS ${ }^{\mathrm{a}, \mathrm{b}}$ \\ aBoston Children's Hospital, Division of Allergy and Immunology, Boston, MA \\ bHarvard Medical School, Boston, MA \\ 'Boston Children's Hospital, Division of Respiratory Diseases, Boston, MA \\ dUniversity of North Carolina School of Medicine, Center for Environmental Medicine, Asthma and \\ Lung Biology, Division of Allergy and Immunology, Chapel Hill, NC \\ eUniversity of Wisconsin School of Medicine and Public Health, Department of Medicine, Division \\ of Allergy, Immunology, Pulmonary, Critical Care, and Sleep Medicine, Madison, WI
}

\begin{abstract}
In this review, we highlight recent studies that advance the knowledge and understanding of the effects of various environmental factors and the associated immune responses in patients with allergic diseases. This review will focus on new literature regarding allergic and immune responses to a variety of environmental factors including aeroallergens, stinging insects, fungi, pollutants, viral respiratory infections, climate change, and microbial exposures.
\end{abstract}

\section{Keywords}

Aeroallergens; fungi; air pollutants; viral respiratory infections; climate change; occupational asthma

\section{INTRODUCTION}

Environmental factors play a major role in the development of allergic sensitization and the persistence of symptomatic allergic diseases. Extensive knowledge has been gained from important birth cohorts(1) and other recent studies. In this selective review, we highlight articles primarily published in 2016 that advance our knowledge of the impact of environmental factors on allergic diseases. We focus on allergens, viral infections, and air pollution which alone or in combination affect allergic diseases, particularly asthma. Major contributions (Table 1) addressed include: 1.) the importance of climate change, and its potential to increase the risk of allergic respiratory diseases in the future; 2 .) sensitization to

Corresponding Author: Wanda Phipatanakul, MD, MS, Division of Allergy and Immunology, Boston Children's, Hospital, 300 Longwood Avenue, Boston, MA 02115, Telephone: 617-355-6117, Fax: 617-730-0248, wanda.phipatanakul@ childrens.harvard.edu.

Publisher's Disclaimer: This is a PDF file of an unedited manuscript that has been accepted for publication. As a service to our customers we are providing this early version of the manuscript. The manuscript will undergo copyediting, typesetting, and review of the resulting proof before it is published in its final citable form. Please note that during the production process errors may be discovered which could affect the content, and all legal disclaimers that apply to the journal pertain. 
Fel $d 1$ and Can $f 1$, especially poly-sensitization, in childhood (age $\leq 4$ years) is significantly associated with allergic symptoms to these pets in adolescence (age 16 years); 3 .) the ability of viral infections to induce fibroblast proliferation; 4.) the multiplicity of effects of air pollution on lung function, epigenetics, airway inflammation, and preterm birth in pregnant women with asthma; and 5.) the role of school specific allergenic exposures in asthma morbidity. Emphasis is also directed at severe asthma in inner city dwellers where allergen exposure and sensitization are significant players in defining asthma phenotypes and are associated with difficult to control asthma. Environmental tobacco smoke exposure in addition to allergens also contributes to the pathogenesis of severe asthma in these populations as well. Understanding the contribution of environmental factors in the inception and progression of allergic diseases as discussed in this review will, hopefully, lead to improved treatments for these conditions.

\section{IgE Responses to Environmental Factors}

$\mathrm{IgE}$ plays a central role in the pathogenesis of allergic diseases. A host of environmental factors influence IgE production. Among these factors, allergens are classically recognized, but viral infections, air pollution, and tobacco smoke can also contribute.(2) Another factor leading to increased plasma IgE levels is high alcohol consumption (ingestion of 28 or more drinks containing 12gm of ETOH/week).(3) But, there was no correlation between these findings and the presence of allergic diseases. Additional studies will be needed to determine the clinical significance of these findings.

Aging can affect allergen specific IgE and total IgE levels in adults. A large study of adults in the European Community Respiratory Health Survey examined the effects of aging on specific IgE levels to common aeroallergens and on total IgE levels over a 20 year period.(4) Aging was associated with lower levels of sensitization to house dust mite and cat allergen and a significant decrease in total $\operatorname{IgE}$ levels. The kinetics of $\operatorname{IgE}$ sensitization decreased differently for different allergens, i.e. grass pollen was less likely to decrease. A better understanding of the mechanisms involved may clarify the cause and treatment of allergic diseases.

Studies of amino acid sequences (peptide epitopes) on allergens indicate that those which acquire enhanced ability to cross-link IgE by oligomerization, aggregation, or expression of repetitive epitopes may gain allergenic potency. It has been proposed that repetitive epitopes represent allergenic associated molecular patterns (AAMPs) by Pali-Scholl and JensenJarolim.(5) In support of this concept, Gieras et al.(6) found that the proximity of $\operatorname{IgE}$ binding sites on an artificial allergen construct enhanced the magnitude of effector cell activation, basophil activation test (BAT) assays, and in vivo inflammation and systemic anaphylaxis in a mouse model. Further investigations into this mechanism, which may regulate allergic inflammation, will be of interest.

Component-resolved diagnostic testing for IgE sensitization to individual allergens has steadily increased in the past several years. An excellent review of the subject has recently appeared.(7) These tests were used to show that sensitization to specific pet allergens correlate with allergic diseases, e.g., Can $f 1$ with persistent rhinitis, Can $f 2$ with asthma, and Fel $d 2$ with an asthma diagnosis.(8) Further evidence from the BAMSE/MeDALL 
study(9) indicates that early childhood sensitization to $\operatorname{Can} f 1, \mathrm{Fel} d 1$, or polysensitization was significantly better than IgE assays using cat or dog extracts in predicting longitudinal development of allergic symptoms. These studies support the benefits of molecular diagnosis of IgE sensitization and mechanisms of allergic diseases.

House dust mites (HDM) are a significant factor in the "allergic march" from sensitization to asthma. A recent report suggests that the inclusion of the HDM allergen, Der $p 23$, in $\operatorname{IgE}$ serologic testing is of value when conventional diagnostics fail.(10) The introduction of house dust mites sublingual immunotherapy (SLIT) tablets can lead to improved treatment of allergic rhinitis in adults and children.(11) In a randomized, double-blind, placebocontrolled phase III trial, standardized HDM SLIT reduced allergic rhinitis symptoms and medication scores and improved quality of life compared to placebo in adults with moderate to severe allergic rhinitis. Further, Roux et al.(12) demonstrated that an environmental exposure chamber was beneficial in establishing the dose-dependent safety and efficacy of sublingual HDM tablet immunotherapy. Such studies can lead to improved diagnostic and therapeutic approaches to HDM sensitivity.

Stinging insect reactions can potentially be fatal; thus, accurate diagnosis is critical. Skin testing, BAT, and in vitro IgE assays have been extensively investigated in order to identify patients at risk for serious reactions to stings. Component-resolved diagnostics are being increasingly utilized to identify high-risk patients, especially those with underlying mast cell disorders.(13) Frick et al. demonstrated that sensitization to Api $m 10$ was a risk factor for treatment failures with honey bee venom since some preparations lack this allergen.(14) The presence of cross-reactive carbohydrate (CCD) antibodies in the sera complicate diagnosis. Schnauzer et al.(15) reported that the sensitivity and specificity of Hymenoptera allergen component-resolved testing depends on the assay employed. One assay (Immulite) was superior for detecting IgE to the honey bee allergy, Api m 1, while another (CAP) was superior for the vespid allergen, Ves $v$ 5. Confirmation of these results will be helpful for diagnosing individual patients and for epidemiological studies.

Allergic reactions to medications are not uncommon. Investigations of alpha-gal have led to new insights into the mechanisms of drug reactions. Two reports in the Journal(16, 17)describe severe immediate-type allergic reactions to pegnivacogin, a PEGylaton RNA aptamer investigation agent being evaluated for the treatment of acute coronary artery syndromes. Pre-formed IgG antibodies to polyethylene glycol (PEG) were detected in the sera of subjects who experienced reactions. The events were associated with evidence of complement activation (decreased CH50, increase C3a, and increased Factor B in sera) and increase tryptase levels (Figure 1). The results suggest an IgG-mediated anaphylactic reaction due to antigen-IgG antibody complexes interacting with Fcy receptors as the mechanism. With a growing interest in genetic factors in drug-hypersensitivity reactions, (18) it will be of interest to see if genetics play a role in these reaction as well.

\section{RESPONSES TO ENVIRONMENTAL FUNGI}

Fungal exposure has been implicated in the development, persistence, and severity of asthma. Interestingly, exposure to a higher fungal diversity in early life may impart a 
protective effect in asthma development.(19) Our companion journal, In Practice, published a series of articles which update newer information on fungal allergy that range from current taxonomy of fungi,(20) innate and adaptive immune responses to fungal allergens and products,(21) and health effects on humans,(22) as well as the evaluation and management of patients with suspected fungal sensitivity.(23) Developments in fungal taxonomy indicate substantial IgE cross-reactivity among fungal species which can aide in the selection of representatives from each taxon for diagnostic testing.(20) Clearly, both innate and adaptive immune responses contribute to the pathogenesis of airway diseases due to fungal exposure. A better understanding of these processes can improve treatment.(21) A symptom questionnaire limited to skin-test panel may assist clinicians in diagnosing fungal allergy; however, there are limitations of fungal immune therapy. These articles will be of particular interest to practicing clinicians.

Studies on the mechanisms of fungal allergy continue. Fungi, particularly Alternaria, have been shown to activate epithelial cells to produce IL-33 and skew ILC2's to produce Th2 cytokines in animal models. In addition, IL-33 has been shown to mediate eosinophilopoesis in response to Alternaria and enhance IL-5 expression by ILC2's in the lungs.(24) This study along with a report by Takeda(25) which demonstrated that human platelets are a source of IL-33 implicate the importance of this cytokine in airway inflammation which may occur in response to environmental allergen exposure. Additionally, the interaction of genetics and fungal exposures has been investigated. Loser et al. used murine models to demonstrate that an asthma susceptibility gene, $O R M D L 3$, contributed to key pathways promoting airway inflammation induced by Alternaria.(26)

Patients with cystic fibrosis (CF) are prone to colonization of the airways with Aspergillus fumigates and subsequent development of ABPA. Diagnostic tests to identify these events were investigated by Gernez et al.(27) using basophil activation tests (BAT). Their report suggests that CD203c up regulation alone was equivalent to a combination of CD63 and CD203c in the BAT for predicting A. fumigates colonization with or without ABPA in CF patients. This group of investigations have also demonstrated that combining a BAT with the CD203c marker and testing for total and specific $A$. fumigates IgE levels allows for the classification of CF patients into three groups: those who are non-sensitized, those with $A$. fumigates sensitization without ABPA, and those with ABPA.(28) Thus, a BAT with $\mathrm{CD} 203 \mathrm{c}$ as a biomarker may be helpful in the management of CF patients. Previous studies have shown that chitinase activity is increased in the sera and BAL fluid of patients with asthma, COPD, and patients with CF lung disease. Hector et al.(29) found that chitinase activity is increased in CF patients compared to healthy controls and that Candida albicans airway colonization in patients with $\mathrm{CF}$ was associated with genetic chitinase deficiency. Interestingly, colonization with $A$. fumigates was not associated with increased chitinase activity. This is another potential biomarker and therapeutic target for CF associated fungal disease. In addition to biomarkers, management of ABPA in CF has been investigated. Antifungal agents have been used to treat ABPA; however, a Cochrane review(30) suggested that due to the lack of properly controlled trials, no conclusions could be made. Further studies will be needed to establish the role of anti-fungals for CF-ABPA. 
Exposure to fungi and bacterial products can result in hypersensitivity pneumonitis (HP) in susceptible individuals. Unfortunately, diagnostic tests for HP have significant limitations. Millon et al.(31) reported the existence of common peptide epitopes on an antigen (dehydrolipoyl dehydrogenase) from Mycobacterium immunogenum and Lichtheimia corymbifera. This group(32) also showed that these peptides could induce INF gamma specific immune responses after stimulation of PBMC's from healthy blood donors. These data suggest that cross-reactivity among HP etiologic agents may lead to improved diagnosis, classification, and preventive measures for HP.

The above reports indicate that significant advances have occurred in the areas of fungal allergy, ABPA in CF, innate immune responses to fungi, and hypersensitivity pneumonitis.

\section{RESPONSES TO OCCUPATIONAL EXPOSURES}

Occupational exposures have a significant impact on asthma and rhinitis morbidity. In a cross-sectional population-based study, Schyllert et al. found that occupational exposure to chemicals substantially increased the risk for rhinitis and asthma in workers exposed to various vapors, gases, and fumes.(33)

A survey of U.S adults with current asthma indicated that up to $48 \%$ may have work-related symptoms.(34) It was estimated that up to 2.7 million people in the US may have asthma caused by or exacerbated by workplace conditions. In this survey, the prevalence of asthma varied from state to state and by occupation. Identification of high risk occupations could lead to improved asthma morbidity.

In addition to workplace exposures, genetic factors also play a significant role in the development of occupational asthma. Rava et al. found that individuals with occupational asthma due to low molecular weight agents and irritants had single nucleotide polymorphisms (SNPs) in genes of the NF- $\mathrm{kB}$ pathway of inflammation. Such studies can result in new therapeutic approaches.(35)

The diagnosis of occupational asthma is often difficult. Pralong et al. reported that in patients suspected of having occupational asthma, a negative methacholine challenge, while the patient is still exposed to the causative agent, virtually excludes the diagnosis.(36) This relatively simple test could reduce the need and expense of additional testing. Lastly, fractional exhaled nitric oxide, FeNO, may have some benefit in diagnosis occupational asthma, since it specifically can aid in "ruling-in" the diagnosis rather than excluding the diagnosis due to a lack of sensitivity.(37)

\section{RESPONSES TO VIRAL INFECTIONS}

Recent research has focused on evaluating the physiologic pathways that help to further understand the well-known link between viral infections and respiratory disease. Human rhinovirus (HRV) infection is a common trigger for asthma and wheezing in children. It has been known that viral triggered wheezing episodes in early life are associated with an increased risk of asthma at early school age; however, new research has demonstrated that early life HRV-triggered wheezing episodes are associated with the persistence of asthma out 
to age 13 years.(38) This finding highlights the possible impact of HRV infection on airway remodeling which was investigated by Shelfoon et al.(39) In doing so, they discovered that HRV-infected human bronchial epithelial cells produced CXCL10 and CXCL8 which are chemotactic for fibroblasts (Figure 2). This leads to the speculation that repeated HRV infections in childhood result in fibroblast deposition in the airways resulting in airway remodeling. Han et al. found that TLR2 is necessary for rhinovirus-induced airway inflammation in both naïve and allergen-sensitized mice.(40) This was demonstrated by mice lacking TLR2 having decreased airway inflammation in response to rhinovirus infection. Furthermore, transfer of TLR $2^{+}$macrophages was sufficient to produce airway inflammation in TLR2 knockout mice. The identification of the importance of TLR2 provides a possible future therapeutic target for viral-induced asthma.

Early-life infections with respiratory syncytial virus (RSV) also play an important role in the development of wheezing and possible asthma in later life. Despite almost universal infection in children in the first few years of life, it is highly uncommon for newborns to be infected with RSV in the first few weeks of life. Jacobino et al. evaluated a panel of amniotic fluid samples and discovered that all the samples contained RSV-specific IgG with RSVneutralizing activity.(41) Thus, early-life protection from respiratory viral infections can be explained by this in utero transfer of amniotic fluid antibodies which are in direct contact with the fetal respiratory tract. Reducing the risk of asthma development after RSV infection has proven to be difficult. Carroll et al. conducted a retrospective cohort investigation and found that higher adherence to RSV immunoprophylaxis during infancy was not associated with decreased rates of asthma in later childhood.(42) The authors recommended larger, prospective cohorts to better evaluate the potential asthma preventative benefits of RSV immunoprophylaxis.

Sokolowska et al. found that patients with severe asthma had decreases in antiviral gene and protein expression in response to low-molecular weight hyaluronon which is generated during tissue inflammation.(43) This provides insight regarding impaired antiviral response in severe asthma.

In recent years, there has been increasing research regarding the interplay between viral infections and allergen exposures on respiratory disease. For example, Mehta et al. demonstrated that infection with rhinovirus inhibits the respiratory epithelium's ability to induce tolerance to inhaled allergens making the lungs more susceptible to inflammation. (44) This interaction may explain why atopy was found to be an important risk factor in not only nonviral asthma exacerbations, but also viral exacerbations in children.(45) Similarly, trials with omalizumab have noted that blocking IgE-mediatred inflammation prevents seasonal peaks in asthma exacerbations related to viral infections. $(46,47)$ Recent research has focused on the mechanism of this viral and allergic interaction. Toussaint et al. used a mouse model to demonstrate that rhinovirus infections triggered the formation of neutrophil extracellular traps (NETs), and that blocking this NETosis protects mice from type-2 immunopathology.(48) Future research will likely focus on continued efforts to disrupt the viral and allergen connection with a goal of improving asthma outcomes. 


\section{RESPONSES TO AIR POLLUTANTS}

Recent studies have expanded on both the epidemiologic risk of exposure to ambient pollutants and further elaborated our understanding of associated immune mechanisms and potential therapeutic targets for patients with asthma. Importantly, as the effect of pollution is rarely experienced in isolation, several co-exposure studies have described potentially important interactions to better characterize the combination of threats to respiratory health experienced by individuals - exposures that may be heightened in the context of climate change and the developing industrial world.

Exposure to pollutants can disrupt human biology at each phase of life. Mendola and colleagues(49) reviewed medical records for 223,502 deliveries in the United States and matched ambient pollution exposure during the course of gestation. Women with asthma and high levels of carbon monoxide $(\mathrm{CO})$ and nitrogen oxides $\left(\mathrm{NO}_{\mathrm{x}}\right)$ exposure either during preconception months or early pregnancy had higher rates of preterm birth than asthmatic women with low levels of these exposures. Particulate matter (PM) exposure was also a risk for early preterm birth ( $<34$ weeks gestation) in pregnant women with asthma. This demonstrates the important maternal-fetal health implications of high pollution exposure in particular vulnerable populations.

Exposure to pollution in infancy and subsequent risk of asthma was determined in the GALA II study, the largest US gene-environment case control study of asthma in minority children.(50) Gaseous and particulate exposures in the first year of life were not significantly associated with atopy in this subgroup of children with asthma in school age and adolescent cohort; however, there was a significant association between ozone $\left(\mathrm{O}_{3}\right)$ exposure in infancy and the development of non-atopic asthma. This reflects a potential non-allergic mechanism of asthma development in minority children. In fact, in healthy subjects, alveolar macrophages are known to have an increased expression of TLR4, TNF-a, and CD-14 following inhalation of ozone at ambient concentrations, both constitutively and in response to LPS.(51) In an unselected birth cohort of children from Stockholm, Sweden, enrolled in the BAMSE study, ambient pollutant exposure estimated by road traffic emissions at participant's resident, school, and daycare locations were significantly associated with airways obstruction.(52) This study confirms prior findings from this group demonstrating that exposure to $\mathrm{NO}_{\mathrm{x}}$ and $\mathrm{PM}_{10}$ in infancy significantly decreased spirometry in adolescence.(53) In the recent study impulse oscillometry was used to assess peripheral airways obstruction and consistently demonstrated that $\mathrm{NO}_{\mathrm{x}}$ exposure in early life was associated with increased airway resistance in all children, especially in those with a diagnosis of asthma at age 16 years. Work by Ierodioakonou et al.(54) found similar relationships between ambient $\mathrm{CO}, \mathrm{NO} 2$, and reduced lung function. They also report the interesting finding that inhaled corticosteroid use led to an augmented negative response to methacholine in subjects with higher $\mathrm{CO}$ exposure, suggesting controller medications may not be beneficial for patients with asthma exposed to certain pollutants. In sum, these studies continue to demonstrate that early life exposure to pollutants can be an early determinant of the asthmatic disease process and may alter airways function throughout childhood. As childhood lung function is known to influence trends throughout life,(55) it is important to identify these potentially modifiable risk factors and targets for therapy. Moreover, while air 
pollution influences later lung function, concurrent exposure to elevated levels of pollutants in adolescence is also directly associated with changes in spirometry. In the Children's Health Study, exposure to $\mathrm{NO}_{\mathrm{x}}, \mathrm{NO}_{2}, \mathrm{NO}$, and $\mathrm{PM}_{2.5}$ each were associated with decrements in $\mathrm{FEV}_{1}$ during the exposure period in adolescent subjects. $\mathrm{FEV}_{1}$ was found to be even lower in patients who had absence of a father in the home, a marker for psychosocial stress. (56) Annual mean NO2 and close proximity to major roadway were found to be associated with asthma symptoms, atopy, and decreased lung function in the middle aged adult cohort in the Tasmanian Longitudinal Health Study.(57) Genetic susceptibility to the adverse effects pollutant exposure was found for null genotype of the Glutathione S-Transferase theta1 (GSTT1) gene, an antioxidant gene which plays an important role in modulating the inflammatory response modulated by reactive oxygen species (ROS).

A closer approximation to natural exposures in human subject, several animal and human studies have examined the effect of interaction of ambient pollutants with other environmental triggers for the development and exacerbation of asthma. Animal models in which mice are exposed to diesel exhaust particles (DEP) and allergens demonstrate that the degree of inflammatory cellular response, including eosinophils, neutrophils, Th2 and IL-13+IL17A+ cells in bronchoalveolar lavage fluid (BALF) and airway hyperresponsiveness is significantly greater than allergen exposure in the absence of DEP. (58) Interestingly, this response was only partially mitigated by steroid treatment, but further reduced when anti-IL17A antibodies were added to the treatment algorithm; this suggests that elevated levels of IL-17A may confer an element of steroid resistance as well as raising IL-17A as a potential therapeutic target in steroid refractory asthma.(58) Furthermore, coexposure of DEP with house dust mite (HDM) but not HDM alone, promotes persistence of increased lung effector and memory Th2 cells, and, in response to HDM challenge 7 weeks later, demonstrate increased BALF Th2 cytokines and increased airway hyperreactivity. De Grove, et al. demonstrated in another mouse model that dual exposure with HDM and DEPs had effects on the epithelial type 2 innate lymphoid cells, ILC2, and the adaptive Th2 cells; however, only the adaptive Th2 cells were necessary and sufficient to induce the allergic inflammatory airway response.(59) The clinical correlate to these dual exposure laboratory studies was found by Brandt, et al.(60) in the Cincinnati Childhood Allergy and Air Pollution Study birth cohort, in which early life exposure to traffic related air pollution, measured as elemental carbon attributable to traffic (ECAT), was associated with earlier sensitization. Children who had high exposure to ECAT at birth and sensitization to HDM, or any allergen, by age 4 years had almost double the prevalence of asthma at age 7 years than those co-exposed with low levels of ECAT.(60) Taken together, these data suggest that pollution exposure early in life in conjunction with allergen exposure may promote a more vigorous inflammatory response during the exposure and a more potent atopic phenotype compared to allergen exposure and sensitization alone. Despite these associations with the development of asthma, Rider and colleagues(61) found that selective allergen exposure to bronchi of asthmatic adults who had breathed diesel exhaust or purified air in a cross-over design study had increased expression of microRNAs and genes associated with bronchial immune responses in bronchial brushing samples; however there was no augmentation of response by the addition of pollutant exposure. The real world relationships between pollution and allergen exposure are important to recognize as the increased greenhouse gas 
accumulation and climate change are anticipated to increase the production, allergenicity, and dispersion of pollen and spores, leading to greater aeroallergen effect on susceptible populations. $(62,63)$

The role of epigenetic modification leading to transgenerational disease susceptibility and environmental exposures was investigated by Somineni, et al.(64) Hypomethylation of the ten-eleven translocation 1 (TET1) gene was found to be significantly associated with childhood asthma in both a primary and replication cohort. However, traffic related air pollution exposure, and DEP exposure in tissue culture, was found to be associated with increased levels of methylation of TET1. Therefore, TET1 gene expression, noted to be influenced by pollution exposure, may have an important role in asthma pathogenesis and a potential target for therapy.(64) In a randomized crossover clinical trial in adults, Clifford and colleagues,(65) found that the changes in bronchial epithelial cell DNA methylation were marginal at 48 hours following controlled DEP inhalation or isolated bronchial allergen challenges, or both. However, when the exposure to allergen and DEP was separated by 4 weeks, a much more robust differential methylation pattern emerged. These patterns differed depending on which exposure occurred first. These data suggest that a priming effect by exposure to either pollution or allergen may instruct the airway response to subsequent exposures. More investigation into these relationships will be needed to reconcile the relationship between environment-methylation-gene-asthma.

Particulate pollution also impairs mechanical function of the epithelial cell barrier of the respiratory tract which may promote further insult by infection or allergen. Human sinonasal epithelial cells exposed to PM10 have a dose dependent destabilization of the epithelial membrane via perturbation of intercellular tight junctions.(66) This destabilization is reversed by activation of nuclear erythroid 2-related factor 2 (Nrf2), a known regulator of oxidative and environmental stress.(66) Ecologic data relating airborne dust and heat in the semiarid Sahel region of Africa where bacterial meningitis is common found that density of dust (measured as low visibility) during hot weather was significantly associated with meningitis rates over an 8 year period.(67) Animal models to further investigate the mechanism found that increased dust exposure in mice with asymptomatic pneumococcal nasopharyngeal carriage increased bacterial burden in the nasopharynx and spread to the lung and brain of the animal. Inflammatory cell response was elicited, but the effectiveness of the response was limited. When elevated temperature was added to the animal model, there was a synergistic effect on animal death. The combination of epithelial disruption and elevated temperatures create an environment conducive to disrupting symbiotic microbial colonization in favor of tissue invasion in a manner that may be taking place in the subSaharan meningitis belt.

\section{ASTHMA AND THE ENVIRONMENT}

On a global level, a perspective on the 2015 United Nations Climate Change Conferences appeared in this journal.(68) This report included an important summary on various ways that climate change has increased the burden of asthma and allergies. Examples include, but are not limited to, elongation and intensification of the pollen season, increased humidity and mold production, and decreased air quality (Table 2). Additionally, there was a recent 
review describing the phenomenon and increased frequency of thunderstorm-related asthma attacks including a projection of a further increase in these extreme weather events in future decades due to climate change.(62) Annesi-Maesano expressed regret that an agreement from the 2015 international meetings was too weak and did not address health effects from climate change; however, the author shared optimism that future international meetings will be better educated to address these topics including asthma and allergies.(68)

On a more local level, there continues to be new and interesting research on the relationship between environmental exposures and asthma morbidity. This interplay has been well documented in lessons learned from the Inner-City Asthma Consortium. This group has focused research on children with asthma living in low-income urban areas where asthma burden is high. Their recent study, Asthma Phenotypes in the Inner City (APIC) has expanded the asthma literature by identifying asthma phenotypes, distinguishing characteristics of difficult-to-control asthma, and describing pathways explaining asthma severity in this population. In one of the primary objectives of the APIC study, Zoratti et al. performed a cluster analysis and identified five clusters where more severe asthma often coclustered with increased allergic inflammation.(69) These findings suggest that environmental allergen avoidance, allergen desensitization, and anti- $\mathrm{T}_{\mathrm{H}} 2$ therapies are appropriate interventions for most inner-city children with asthma. In contrast, there was one previously unreported phenotype that was identified and characterized by frequent asthma symptoms despite only minimal allergic inflammation. These children may benefit from evaluation of uncontrolled comorbidities or unrecognized non-allergic triggers, such as environmental tobacco exposure. Additionally, it was found that approximately $40 \%$ of the children in the cohort had difficult-to-control asthma despite good adherence with controller therapies.(70) In agreement with the findings of the cluster analysis, the children with the difficult-to-control asthma were able to be identified early in the course of treatment by pulmonary physiology measures and allergic markers such as rhinitis scores, total serum $\mathrm{IgE}$, and allergen sensitization. Thus, recognition of the amount of allergic inflammation in an inner-city child may not only assist in guiding allergen avoidance strategies, but may also predict children in need of closer monitoring due to difficult- to-control asthma. Finally, Lui et al.(71) investigated pathways through which asthma risk factors contribute to asthma severity in these inner-city children. In this analysis, it was discovered that the allergy pathway and tobacco smoke exposure pathway exerted the predominant effects on asthma severity. These findings further underscore the importance of environmental exposures in inner-city asthma.

In addition to allergic triggers, there are other environmental influences that continue to be identified as important factors in asthma development and control. Stein et al. found that children raised in an Amish environment with traditional farming were exposed to a rich environment of microbes and had low rates of asthma.(72) In an experimental model, these researchers showed that the protective effect of that specific environment was due to activation of the innate immune response. Conversely, this suggests that development of asthma may be enhanced when innate immune stimulation is absent or weak. In the APIC study, environmental tobacco smoke was associated with worsening pulmonary physiology and increased asthma severity.(71) Horner et al.(73) reported that increased child-reported stress during the day was associated with an increased likelihood of awakening that night 
from asthma, but not awakening for a reason other than asthma. Finally, a study of inner-city schools discovered that increased exposures to mouse allergen in the schools was associated with increased asthma symptom days and decreased lung function.(74) A surprising finding of this study was that the association of mouse allergen exposure and asthma outcomes was significant irrespective of sensitization status. This indicates that high levels of mouse allergen exposure may be a direct irritant or result in non-allergic-mediated inflammation even in nonsensitized individual.

Research continues on environmental interventions to reduce harmful exposures and improve asthma outcomes. Rabito et al.(75) evaluated a single intervention, insecticidal bait, to reduce cockroach exposure and improve asthma outcomes in children. When compared to control homes, intervention homes had significantly fewer cockroaches at follow up and this was associated with improved asthma outcomes.(75) In contrast, other recent randomized, controlled, environmental allergen intervention trials have not seen significant differences between intervention and control homes. For example, DiMango et al.(76) demonstrated that targeted household allergen reduction strategies effectively reduced levels of all measured allergens (cockroach, mouse, dust mites, cat, dog), but did not result in a further reduction in asthma controller therapy when compared to the control group. Similarly, Matsui et al.(77) implemented a randomized home intervention trial targeted for mouse allergen reduction and discovered that professional integrated pest management did not result in a significant difference in maximal asthma symptoms days when compared to participants given education alone. Many participants in both groups experienced significant reductions in household mouse allergen exposure and this reduction was associated with improved asthma outcomes; however there were not significant differences between the intervention group and education group. The results of these two studies not finding a significant difference highlights a difficulty with home environment intervention trials: namely that both groups (intervention and control) often improve. The reason for this is likely due to one of two factors: (1) the control groups also experience a significant reduction in certain household allergen levels possibly a result of subject-initiated preparation in anticipation of household inspections, and/or (2) both groups experience improvements in asthma measures possibly due to enrollment in a study with regular follow ups and encouragement of good adherence to freely provided medications. Future household intervention studies will need to continue to develop strategies to overcome these possible hurdles in order to isolate and examine the specific impact of environmental interventions. Finally, there is opportunity for environmental intervention studies outside of the home. Jhun et al.(78) demonstrated that classroom-based air cleaners led to significant reductions in $\mathrm{PM}_{2.5}$ and black carbon when compared to control classrooms. This highlights the school as a location for future environmental intervention studies aimed at improving asthma in children.

\section{SUMMARY}

In this review, we examined recent literature focused on environmental exposures and the links to allergic and respiratory diseases. There were important findings regarding $\operatorname{IgE}$ responses to environmental stimuli, mechanisms of fungal allergy, inflammatory responses to viral respiratory infections, respiratory effects of air pollution exposures, and the impact of early life exposures on asthma development. We have highlighted and summarized some 
of these findings in Figure 3. The understanding of the association of environmental exposure and clinical outcomes has led to new strategies for treatment and intervention. It is expected that future research will continue to expand on these strategies to improve the respiratory health for all.

\section{Acknowledgments}

\section{Funding:}

This study was supported by grants K23AI104780, K23AI106945, and K24AI106822 from the National Institutes of Health.

\section{References}

1. Jackson DJ, Gern JE, Lemanske RF Jr. Lessons learned from birth cohort studies conducted in diverse environments. J Allergy Clin Immunol. 2017; 139(2):379-86. [PubMed: 28183432]

2. Froidure A, Mouthuy J, Durham SR, Chanez P, Sibille Y, Pilette C. Asthma phenotypes and IgE responses. Eur Respir J. 2016; 47(1):304-19. [PubMed: 26677936]

3. Lomholt FK, Nielsen SF, Nordestgaard BG. High alcohol consumption causes high IgE levels but not high risk of allergic disease. J Allergy Clin Immunol. 2016; 138(5):1404-13. e13. [PubMed: 27464961]

4. Amaral AF, Newson RB, Abramson MJ, Anto JM, Bono R, Corsico AG, et al. Changes in IgE sensitization and total IgE levels over 20 years of follow-up. J Allergy Clin Immunol. 2016; 137(6): 1788-95. e9. [PubMed: 26586040]

5. Pali-Scholl I, Jensen-Jarolim E. The concept of allergen-associated molecular patterns (AAMP). Curr Opin Immunol. 2016; 42:113-8. [PubMed: 27619413]

6. Gieras A, Linhart B, Roux KH, Dutta M, Khodoun M, Zafred D, et al. IgE epitope proximity determines immune complex shape and effector cell activation capacity. J Allergy Clin Immunol. 2016; 137(5):1557-65. [PubMed: 26684291]

7. Matricardi PM, Kleine-Tebbe J, Hoffmann HJ, Valenta R, Hilger C, Hofmaier S, et al. EAACI Molecular Allergology User's Guide. Pediatr Allergy Immunol. 2016; 27(Suppl 23):1-250. [PubMed: 27288833]

8. Uriarte SA, Sastre J. Clinical relevance of molecular diagnosis in pet allergy. Allergy. 2016; 71(7): 1066-8. [PubMed: 27108666]

9. Asarnoj A, Hamsten C, Waden K, Lupinek C, Andersson N, Kull I, et al. Sensitization to cat and dog allergen molecules in childhood and prediction of symptoms of cat and dog allergy in adolescence: A BAMSE/MeDALL study. J Allergy Clin Immunol. 2016; 137(3):813-21. e7. [PubMed: 26686472]

10. Becker S, Schlederer T, Kramer MF, Haack M, Vrtala S, Resch Y, et al. Real- Life Study for the Diagnosis of House Dust Mite Allergy - The Value of Recombinant Allergen-Based IgE Serology. Int Arch Allergy Immunol. 2016; 170(2):132-7. [PubMed: 27505432]

11. Demoly P, Emminger W, Rehm D, Backer V, Tommerup L, Kleine-Tebbe J. Effective treatment of house dust mite-induced allergic rhinitis with 2 doses of the SQ HDM SLIT-tablet: Results from a randomized, double-blind, placebo-controlled phase III trial. J Allergy Clin Immunol. 2016; 137(2):444-51. e8. [PubMed: 26292778]

12. Roux M, Devillier P, Yang WH, Montagut A, Abiteboul K, Viatte A, et al. Efficacy and safety of sublingual tablets of house dust mite allergen extracts: Results of a dose-ranging study in an environmental exposure chamber. J Allergy Clin Immunol. 2016; 138(2):451-8. e5. [PubMed: 27289490]

13. Michel J, Brockow K, Darsow U, Ring J, Schmidt-Weber CB, Grunwald T, et al. Added sensitivity of component-resolved diagnosis in hymenoptera venom-allergic patients with elevated serum tryptase and/or mastocytosis. Allergy. 2016; 71(5):651-60. [PubMed: 26836051] 
14. Frick M, Fischer J, Helbling A, Rueff F, Wieczorek D, Ollert M, et al. Predominant Api m 10 sensitization as risk factor for treatment failure in honey bee venom immunotherapy. J Allergy Clin Immunol. 2016; 138(6):1663-71. e9. [PubMed: 27372568]

15. Schrautzer C, Bokanovic D, Hemmer W, Lang R, Hawranek T, Schwarz I, et al. Sensitivity and specificity of Hymenoptera allergen components depend on the diagnostic assay employed. J Allergy Clin Immunol. 2016; 137(5):1603-5. [PubMed: 26768412]

16. Ganson NJ, Povsic TJ, Sullenger BA, Alexander JH, Zelenkofske SL, Sailstad JM, et al. Preexisting anti-polyethylene glycol antibody linked to first-exposure allergic reactions to pegnivacogin, a PEGylated RNA aptamer. J Allergy Clin Immunol. 2016; 137(5):1610-3. e7. [PubMed: 26688515]

17. Povsic TJ, Lawrence MG, Lincoff AM, Mehran R, Rusconi CP, Zelenkofske SL, et al. Pre-existing anti-PEG antibodies are associated with severe immediate allergic reactions to pegnivacogin, a PEGylated aptamer. J Allergy Clin Immunol. 2016; 138(6):1712-5. [PubMed: 27522158]

18. Cornejo-Garcia JA, Oussalah A, Blanca M, Gueant-Rodriguez RM, Mayorga C, Waton J, et al. Genetic Predictors of Drug Hypersensitivity. Curr Pharm Des. 2016; 22(45):6725-33. [PubMed: 27779086]

19. Sheehan WJ, Phipatanakul W. Indoor allergen exposure and asthma outcomes. Curr Opin Pediatr. 2016; 28(6):772-7. [PubMed: 27653703]

20. Levetin E, Horner WE, Scott JA. Environmental Allergens W. Taxonomy of Allergenic Fungi. J Allergy Clin Immunol Pract. 2016; 4(3):375-85. e1. [PubMed: 26725152]

21. Williams PB, Barnes CS, Portnoy JM. Environmental Allergens W. Innate and Adaptive Immune Response to Fungal Products and Allergens. J Allergy Clin Immunol Pract. 2016; 4(3):386-95. [PubMed: 26755096]

22. Baxi SN, Portnoy JM, Larenas-Linnemann D, Phipatanakul W. Environmental Allergens W. Exposure and Health Effects of Fungi on Humans. J Allergy Clin Immunol Pract. 2016; 4(3):396404. [PubMed: 26947460]

23. Larenas-Linnemann D, Baxi S, Phipatanakul W, Portnoy JM. Environmental Allergens W. Clinical Evaluation and Management of Patients with Suspected Fungus Sensitivity. J Allergy Clin Immunol Pract. 2016; 4(3):405-14. [PubMed: 26755100]

24. Anderson EL, Kobayashi T, Iijima K, Bartemes KR, Chen CC, Kita H. IL-33 mediates reactive eosinophilopoiesis in response to airborne allergen exposure. Allergy. 2016; 71(7):977-88. [PubMed: 26864308]

25. Takeda T, Unno H, Morita H, Futamura K, Emi-Sugie M, Arae K, et al. Platelets constitutively express IL-33 protein and modulate eosinophilic airway inflammation. J Allergy Clin Immunol. 2016; 138(5):1395-403. e6. [PubMed: 27056266]

26. Loser S, Gregory LG, Zhang Y, Schaefer K, Walker SA, Buckley J, et al. Pulmonary ORMDL3 is critical for induction of Alternaria-induced allergic airways disease. J Allergy Clin Immunol. 2017; 139(5):1496-507. e3. [PubMed: 27623174]

27. Gernez Y, Waters J, Tirouvanziam R, Herzenberg L, Moss R. Basophil activation test determination of CD63 combined with CD203c is not superior to CD203c alone in identifying allergic bronchopulmonary aspergillosis in cystic fibrosis. J Allergy Clin Immunol. 2016; 138(4):1195-6. [PubMed: 27215492]

28. Mirkovic B, Lavelle GM, Azim AA, Helma K, Gargoum FS, Molloy K, et al. The basophil surface marker CD203c identifies Aspergillus species sensitization in patients with cystic fibrosis. $\mathbf{J}$ Allergy Clin Immunol. 2016; 137(2):436-43. e9. [PubMed: 26388311]

29. Hector A, Chotirmall SH, Lavelle GM, Mirkovic B, Horan D, Eichler L, et al. Chitinase activation in patients with fungus-associated cystic fibrosis lung disease. J Allergy Clin Immunol. 2016; 138(4):1183-9. e4. [PubMed: 27056270]

30. Elphick HE, Southern KW. Antifungal therapies for allergic bronchopulmonary aspergillosis in people with cystic fibrosis. Cochrane Database Syst Rev. 2016; 11:CD002204. [PubMed: 27820955]

31. Millon L, Rognon B, Valot B, Barrera C, Bellanger AP, Roussel S, et al. Common peptide epitopes induce cross-reactivity in hypersensitivity pneumonitis serodiagnosis. J Allergy Clin Immunol. 2016; 138(6):1738-41. e6. [PubMed: 27498359] 
32. Bellanger AP, Lignon T, Godet Y, Rognon B, Reboux G, Gbaguidi-Haore H, et al. Fungal peptides from pneumonitis hypersensitivity etiologic agents are able to induce specific cellular immune response. J Immunol Methods. 2017; 440:67-73. [PubMed: 27876506]

33. Schyllert C, Ronmark E, Andersson M, Hedlund U, Lundback B, Hedman L, et al. Occupational exposure to chemicals drives the increased risk of asthma and rhinitis observed for exposure to vapours, gas, dust and fumes: a cross-sectional population-based study. Occup Environ Med. 2016; 73(10):663-9. [PubMed: 27466615]

34. Dodd KE, Mazurek JM. Asthma Among Employed Adults, by Industry and Occupation-- 21 States, 2013. MMWR Morb Mortal Wkly Rep. 2016; 65(47):1325-31. [PubMed: 27906909]

35. Rava M, Ahmed I, Kogevinas M, Le Moual N, Bouzigon E, Curjuric I, et al. Genes Interacting with Occupational Exposures to Low Molecular Weight Agents and Irritants on Adult-Onset Asthma in Three European Studies. Environ Health Perspect. 2017; 125(2):207-14. [PubMed: 27504716]

36. Pralong JA, Lemiere C, Rochat T, L'Archeveque J, Labrecque M, Cartier A. Predictive value of nonspecific bronchial responsiveness in occupational asthma. J Allergy Clin Immunol. 2016; 137(2):412-6. [PubMed: 26220529]

37. Karrasch S, Linde K, Rucker G, Sommer H, Karsch-Volk M, Kleijnen J, et al. Accuracy of FENO for diagnosing asthma: a systematic review. Thorax. 2017; 72(2):109-16. [PubMed: 27388487]

38. Rubner FJ, Jackson DJ, Evans MD, Gangnon RE, Tisler CJ, Pappas TE, et al. Early life rhinovirus wheezing, allergic sensitization, and asthma risk at adolescence. J Allergy Clin Immunol. 2017; 139(2):501-7. [PubMed: 27312820]

39. Shelfoon C, Shariff S, Traves SL, Kooi C, Leigh R, Proud D. Chemokine release from human rhinovirus-infected airway epithelial cells promotes fibroblast migration. J Allergy Clin Immunol. 2016; 138(1):114-22. e4. [PubMed: 26883463]

40. Han M, Chung Y, Young Hong J, Rajput C, Lei J, Hinde JL, et al. Toll-like receptor 2-expressing macrophages are required and sufficient for rhinovirus-induced airway inflammation. J Allergy Clin Immunol. 2016; 138(6):1619-30. [PubMed: 27084403]

41. Jacobino SR, Nederend M, Hennus M, Houben ML, Ngwuta JO, Viveen M, et al. Human amniotic fluid antibodies protect the neonate against respiratory syncytial virus infection. J Allergy Clin Immunol. 2016; 138(5):1477-80. e5. [PubMed: 27448445]

42. Carroll KN, Gebretsadik T, Escobar GJ, Wu P, Li SX, Walsh EM, et al. Respiratory syncytial virus immunoprophylaxis in high-risk infants and development of childhood asthma. J Allergy Clin Immunol. 2017; 139(1):66-71. e3. [PubMed: 27212083]

43. Sokolowska M, Chen LY, Liu Y, Martinez-Anton A, Logun C, Alsaaty S, et al. Dysregulation of lipidomic profile and antiviral immunity in response to hyaluronan in patients with severe asthma. J Allergy Clin Immunol. 2017; 139(4):1379-83. [PubMed: 27826094]

44. Mehta AK, Duan W, Doerner AM, Traves SL, Broide DH, Proud D, et al. Rhinovirus infection interferes with induction of tolerance to aeroantigens through OX40 ligand, thymic stromal lymphopoietin, and IL-33. J Allergy Clin Immunol. 2016; 137(1):278-88. e6. [PubMed: 26100084]

45. Coleman AT, Jackson DJ, Gangnon RE, Evans MD, Lemanske RF Jr, Gern JE. Comparison of risk factors for viral and nonviral asthma exacerbations. J Allergy Clin Immunol. 2015; 136(4):1127-9. e4. [PubMed: 26194546]

46. Busse WW, Morgan WJ, Gergen PJ, Mitchell HE, Gern JE, Liu AH, et al. Randomized trial of omalizumab (anti-IgE) for asthma in inner-city children. N Engl J Med. 2011; 364(11):1005-15. [PubMed: 21410369]

47. Teach SJ, Gill MA, Togias A, Sorkness CA, Arbes SJ Jr, Calatroni A, et al. Preseasonal treatment with either omalizumab or an inhaled corticosteroid boost to prevent fall asthma exacerbations. J Allergy Clin Immunol. 2015; 136(6):1476-85. [PubMed: 26518090]

48. Toussaint M, Jackson DJ, Swieboda D, Guedan A, Tsourouktsoglou TD, Ching YM, et al. Host DNA released by NETosis promotes rhinovirus-induced type- 2 allergic asthma exacerbation. Nat Med. 2017; 23(6):681-91. [PubMed: 28459437]

J Allergy Clin Immunol. Author manuscript; available in PMC 2018 December 01. 
49. Mendola P, Wallace M, Hwang BS, Liu D, Robledo C, Mannisto T, et al. Preterm birth and air pollution: Critical windows of exposure for women with asthma. J Allergy Clin Immunol. 2016; 138(2):432-40. e5. [PubMed: 26944405]

50. Nishimura KK, Iwanaga K, Oh SS, Pino-Yanes M, Eng C, Keswani A, et al. Early-life ozone exposure associated with asthma without sensitization in Latino children. J Allergy Clin Immunol. 2016; 138(6):1703-6. e1. [PubMed: 27423496]

51. Frush BW, Li Z, Stiles JV, Cotter SF, Shofer SL, Foster WM, et al. Ozone primes alveolar macrophage-derived innate immunity in healthy human subjects. J Allergy Clin Immunol. 2016; 138(4):1213-5. e1. [PubMed: 27325435]

52. Schultz ES, Hallberg J, Gustafsson PM, Bottai M, Bellander T, Bergstrom A, et al. Early life exposure to traffic-related air pollution and lung function in adolescence assessed with impulse oscillometry. J Allergy Clin Immunol. 2016; 138(3):930-2. e5. [PubMed: 27297996]

53. Schultz ES, Hallberg J, Bellander T, Bergstrom A, Bottai M, Chiesa F, et al. Early-Life Exposure to Traffic-related Air Pollution and Lung Function in Adolescence. Am J Respir Crit Care Med. 2016; 193(2):171-7. [PubMed: 26397124]

54. Ierodiakonou D, Zanobetti A, Coull BA, Melly S, Postma DS, Boezen HM, et al. Ambient air pollution, lung function, and airway responsiveness in asthmatic children. J Allergy Clin Immunol. 2016; 137(2):390-9. [PubMed: 26187234]

55. McGeachie MJ, Yates KP, Zhou X, Guo F, Sternberg AL, Van Natta ML, et al. Patterns of Growth and Decline in Lung Function in Persistent Childhood Asthma. N Engl J Med. 2016; 374(19): 1842-52. [PubMed: 27168434]

56. Bandoli G, von Ehrenstein O, Ghosh JK, Ritz B. Synergistic effects of air pollution and psychosocial stressors on adolescent lung function. J Allergy Clin Immunol. 2016; 138(3):918-20. e4. [PubMed: 27262744]

57. Bowatte G, Lodge CJ, Knibbs LD, Lowe AJ, Erbas B, Dennekamp M, et al. Traffic-related air pollution exposure is associated with allergic sensitization, asthma, and poor lung function in middle age. J Allergy Clin Immunol. 2017; 139(1):122-9. e1. [PubMed: 27372567]

58. Brandt EB, Khurana Hershey GK. A combination of dexamethasone and anti-IL-17A treatment can alleviate diesel exhaust particle-induced steroid insensitive asthma. J Allergy Clin Immunol. 2016; 138(3):924-8. e2. [PubMed: 27264458]

59. De Grove KC, Provoost S, Hendriks RW, McKenzie AN, Seys LJ, Kumar S, et al. Dysregulation of type 2 innate lymphoid cells and TH2 cells impairs pollutant-induced allergic airway responses. $\mathrm{J}$ Allergy Clin Immunol. 2017; 139(1):246-57. e4. [PubMed: 27315767]

60. Brandt EB, Biagini Myers JM, Acciani TH, Ryan PH, Sivaprasad U, Ruff B, et al. Exposure to allergen and diesel exhaust particles potentiates secondary allergen-specific memory responses, promoting asthma susceptibility. J Allergy Clin Immunol. 2015; 136(2):295-303. e7. [PubMed: 25748065]

61. Rider CF, Yamamoto M, Gunther OP, Hirota JA, Singh A, Tebbutt SJ, et al. Controlled diesel exhaust and allergen coexposure modulates microRNA and gene expression in humans: Effects on inflammatory lung markers. J Allergy Clin Immunol. 2016; 138(6):1690-700. [PubMed: 27283384]

62. D'Amato G, Annesi Maesano I, Molino A, Vitale C, D'Amato M. Thunderstorm-related asthma attacks. J Allergy Clin Immunol. 2017; 139(6):1786-7. [PubMed: 28342913]

63. Schiavoni G, D'Amato G, Afferni C. The dangerous liaison between pollens and pollution in respiratory allergy. Ann Allergy Asthma Immunol. 2017; 118(3):269-75. [PubMed: 28143681]

64. Somineni HK, Zhang X, Biagini Myers JM, Kovacic MB, Ulm A, Jurcak N, et al. Ten-eleven translocation 1 (TET1) methylation is associated with childhood asthma and traffic-related air pollution. Allergy Clin Immunol. 2016; 137(3):797-805. e5.

65. Clifford RL, Jones MJ, MacIsaac JL, McEwen LM, Goodman SJ, Mostafavi S, et al. Inhalation of diesel exhaust and allergen alters human bronchial epithelium DNA methylation. J Allergy Clin Immunol. 2017; 139(1):112-21. [PubMed: 27321436]

66. London NR Jr, Tharakan A, Rule AM, Lane AP, Biswal S, Ramanathan M Jr. Air pollutantmediated disruption of sinonasal epithelial cell barrier function is reversed by activation of the Nrf2 pathway. J Allergy Clin Immunol. 2016; 138(6):1736-8. e4. [PubMed: 27576127] 
67. Jusot JF, Neill DR, Waters EM, Bangert M, Collins M, Bricio Moreno L, et al. Airborne dust and high temperatures are risk factors for invasive bacterial disease. J Allergy Clin Immunol. 2017; 139(3):977-86. e2. [PubMed: 27523432]

68. Annesi-Maesano I. United Nations Climate Change Conferences: COP21 a lost opportunity for asthma and allergies and preparing for COP22. J Allergy Clin Immunol. 2016; 138(1):57-8. [PubMed: 27373326]

69. Zoratti EM, Krouse RZ, Babineau DC, Pongracic JA, O'Connor GT, Wood RA, et al. Asthma phenotypes in inner-city children. J Allergy Clin Immunol. 2016; 138(4):1016-29. [PubMed: 27720016]

70. Pongracic JA, Krouse RZ, Babineau DC, Zoratti EM, Cohen RT, Wood RA, et al. Distinguishing characteristics of difficult-to-control asthma in inner-city children and adolescents. J Allergy Clin Immunol. 2016; 138(4):1030-41. [PubMed: 27720017]

71. Liu AH, Babineau DC, Krouse RZ, Zoratti EM, Pongracic JA, O'Connor GT, et al. Pathways through which asthma risk factors contribute to asthma severity in inner-city children. J Allergy Clin Immunol. 2016; 138(4):1042-50. [PubMed: 27720018]

72. Stein MM, Hrusch CL, Gozdz J, Igartua C, Pivniouk V, Murray SE, et al. Innate Immunity and Asthma Risk in Amish and Hutterite Farm Children. N Engl J Med. 2016; 375(5):411-21. [PubMed: 27518660]

73. Horner CC, Dula C, Bacharier LB, Garbutt JM, Gonzalez C, Deych E, et al. Daily global stress is associated with nocturnal asthma awakenings in school-age children. J Allergy Clin Immunol. 2016; 138(4):1196-9. e3. [PubMed: 27246525]

74. Sheehan WJ, Permaul P, Petty CR, Coull BA, Baxi SN, Gaffin JM, et al. Association Between Allergen Exposure in Inner-City Schools and Asthma Morbidity Among Students. JAMA Pediatr. 2017; 171(1):31-8. [PubMed: 27893060]

75. Rabito FA, Carlson JC, He H, Werthmann D, Schal C. A single intervention for cockroach control reduces cockroach exposure and asthma morbidity in children. J Allergy Clin Immunol. 2017

76. DiMango E, Serebrisky D, Narula S, Shim C, Keating C, Sheares B, et al. Individualized Household Allergen Intervention Lowers Allergen Level But Not Asthma Medication Use: A Randomized Controlled Trial. J Allergy Clin Immunol Pract. 2016; 4(4):671-9. e4. [PubMed: 27025297]

77. Matsui EC, Perzanowski M, Peng RD, Wise RA, Balcer-Whaley S, Newman M, et al. Effect of an Integrated Pest Management Intervention on Asthma Symptoms Among Mouse-Sensitized Children and Adolescents With Asthma: A Randomized Clinical Trial. JAMA. 2017; 317(10): 1027-36. [PubMed: 28264080]

78. Jhun I, Gaffin JM, Coull BA, Huffaker MF, Petty CR, Sheehan WJ, et al. School Environmental Intervention to Reduce Particulate Pollutant Exposures for Children with Asthma. J Allergy Clin Immunol Pract. 2017; 5(1):154-9. e3. [PubMed: 27641483] 

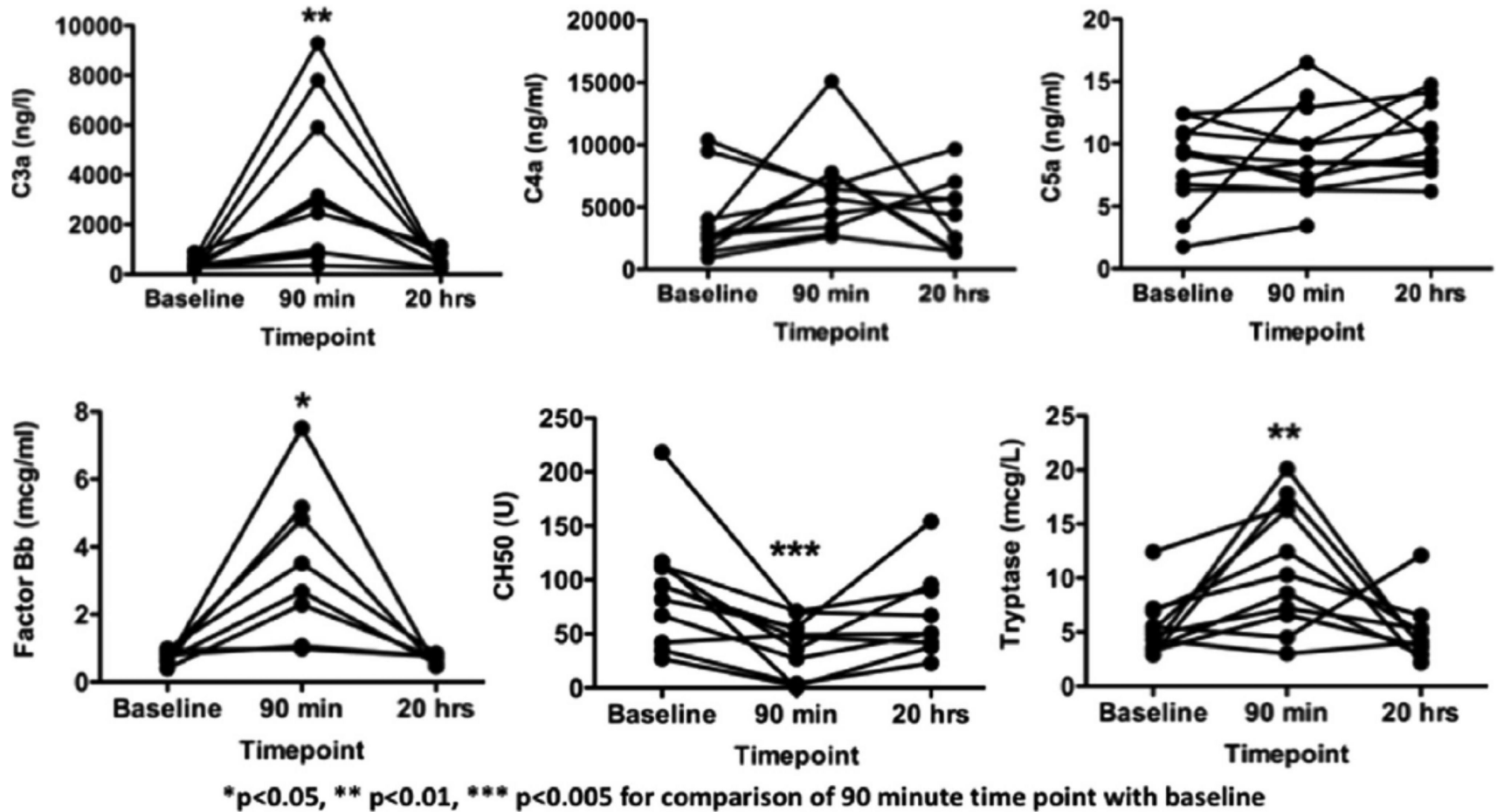

"p<0.05, ** $p<0.01, * * * p<0.005$ for comparison of 90 minute time point with baseline

FIGURE 1.

Changes in individual complement components and tryptase levels in patients with severe immediate acute reactions to pegnivacogin with pre-formed antibodies to PEG (polyethylene glycol).

Povsic TJ et al. JACI. 2016. 138: 1712-1715 

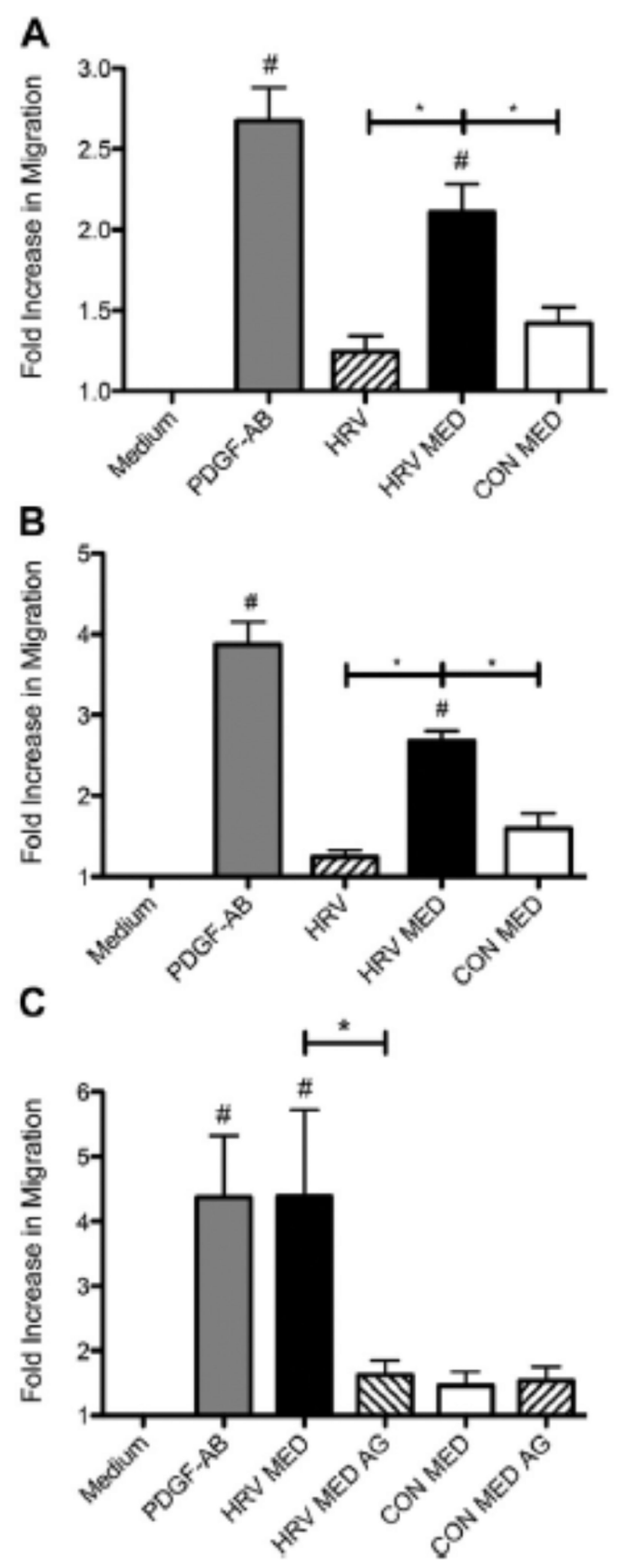

FIGURE 2.

Conditioned medium from epithelial cells infected with HRV (HRV MED) is chemotactic for fibroblasts. A and B, HRV MED significantly increased migration of human bronchial fibroblasts relative to medium alone, conditioned medium from uninfected cells (CON MED), or HRV alone in the Boyden chamber ( $n=4$; Figure 1, A) or the xCELLigence system $(\mathrm{n}=5$; Figure 1, B). C, Abolition of the chemotactic gradient abrogated migration to HRV MED. \# $\mathrm{p}<0.05$ versus medium alone. ${ }^{*} \mathrm{p}<0.05$ versus other treatments. Conditions with abolished gradient are indicated by AG.

Shelfoon et al. JACI. 2016. 138: 114-122 


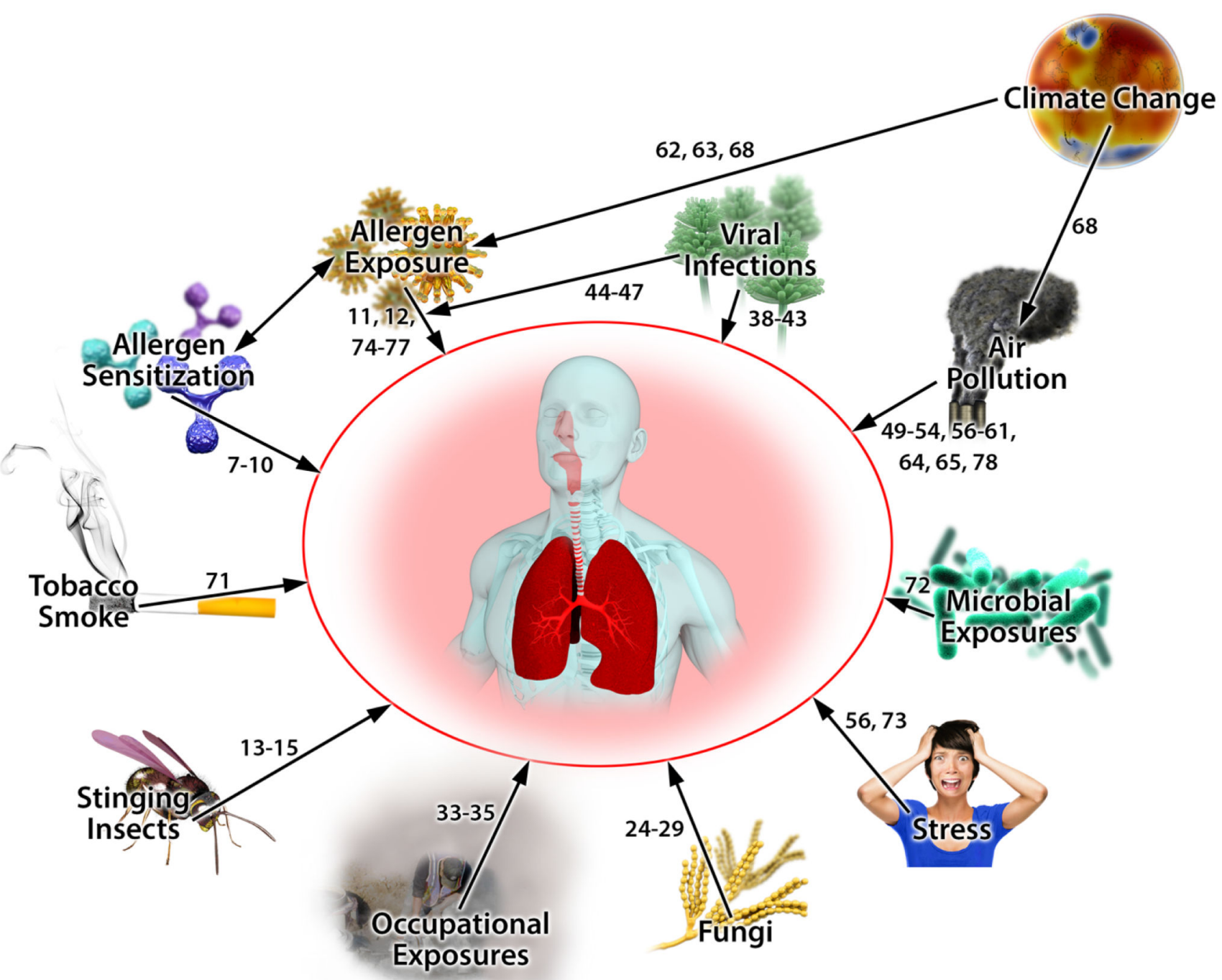

FIGURE 3.

This figure provides a summary of some of the areas of recent advancement in this field. The numbers indicate the reference numbers in this current article. Certainly, there are other influences on allergic and respiratory diseases which have not been reviewed in this article. 


\section{TABLE 1}

\section{Key Advances}

\begin{tabular}{|c|c|}
\hline Advances & References \\
\hline Proximity of IgE epitopes on an allergen affects its allergenic activity. & Gieras at al.(6) \\
\hline $\begin{array}{l}\text { Early life sensitization to Fel d } 1 \text { and Can } \mathrm{f} 1 \text { or polysensitization to cat and dog allergens can predict the } \\
\text { development of allergic symptoms in adolescence. }\end{array}$ & Asarnoj et al.(9) \\
\hline Sensitivity and specificity of Hymenopteral allergen components depend on the diagnostic assay. & Schrautzer et al.(15) \\
\hline Chitinases may represent a novel biomarker for cystic fibrosis-associated fungal disease. & Hector et al.(29) \\
\hline $\begin{array}{l}\text { Early life human rhinovirus-triggered wheezing episodes continue to be important in the development of } \\
\text { asthma as they can result in airway remodeling and have been associated with the persistence of asthma } \\
\text { into adolescence. }\end{array}$ & $\begin{array}{l}\text { Rubner et al.,(38) Shelfoon et al. } \\
\text { (39) }\end{array}$ \\
\hline $\begin{array}{l}\text { Air pollution exposure early in life in conjunction with allergen exposure may promote a stronger } \\
\text { inflammatory response as compared to allergen exposure alone. }\end{array}$ & Brandt et al.,(58) Brandt et al.(60) \\
\hline Climate change has increased the burden of asthma and allergies in a variety of ways. & Annesi-Maesano(68) \\
\hline $\begin{array}{l}\text { Exposure to traditional farming environments can be protective against the development of asthma by } \\
\text { activating innate immune responses. }\end{array}$ & Stein et al.(72) \\
\hline $\begin{array}{l}\text { Exposure to mouse allergen in inner-city schools was associated with increased asthma symptom days in } \\
\text { the students with asthma irrespective of sensitization status. }\end{array}$ & Sheehan et al.(74) \\
\hline $\begin{array}{l}\text { Results of randomized home allergen reduction intervention trials can be affected by motivations in the } \\
\text { control groups. }\end{array}$ & $\begin{array}{l}\text { Dimango et al.,(76) Matsui et al. } \\
\text { (77) }\end{array}$ \\
\hline
\end{tabular}


TABLE 2

The Effects of Climate Change on Triggers for Allergic and Respiratory Diseases

- $\quad$ Earlier onset of the pollen season

- Elongation of the pollen season

- Increased plant growth

- Increased pollen allergen produced by each plant

- Increased humidity and increased mold allergen production

- Decreased air quality and increased air pollution

- Changing habitats for stinging insects

- More extreme weather events - i.e. heat waves, thunderstorm asthma 